\title{
Francisco Leitão Ferreira, poeta e académico
}

\author{
Francisco Leitão Ferreira, poet and scholar
}

Maria do Socorro Fernandes de Carvalho ${ }^{1}$

Resumo: Este texto noticia a existência de livros de Francisco Leitão Ferreira (1667 a 1735) na Biblioteca Nacional do Brasil, no Rio de Janeiro. A partir deste acervo, estudase a produção letrada deste importante acadêmico e da inserção de sua obra na cena letrada da Lisboa setecentista. Estuda-se sua produção de poesia, pouco conhecida; e sua produção como pensador, em específico a composição da síntese especulativa das letras seiscentistas, conforme doutrinação importada em Portugal da Itália e da Espanha, por ele elaborada como acadêmico da Academia dos Anônimos de Lisboa: Nova Arte de Conceitos, 1715 e 1721.

Palavras-chave: Poética. Retórica. Nova arte de Conceitos. Academia. Século XVIII.

Abstract: This text notices the existence of books by Francisco Leitão Ferreira (1667 to 1735) in the National Library of Brazil, in Rio de Janeiro. From this collection, we study the literary production of this important academic and the insertion of his work in the literary scene of Lisbon in the early eighteenth century. We study also his production as a thinker, in particular the composition of the speculative synthesis of the seventeenthcentury letters, according to indoctrination imported into Portugal from Italy and Spain, which he wrote as an academician of the Academia dos Anonymous of Lisbon: New Art of Concepts, 1715 and 1721.

Keywords: Poetics. Rhetoric. New art of Concepts. Academy. Eighteenth century.

1 Professora associada do Departamento de Letras da Universidade Federal de São Paulo (Unifesp). É autora do livro Poesia de agudeza em Portugal (2007). 
Admiró lo culto de su trato.

(Baltasar Gracián)

Cantiga feita nos grandes campos de Roma

(...) Passando, à força de braços, Por uns, por outros empeços,

Maria do

Socorro

Fernandes de

Carvalho

A Biblioteca Nacional do Brasil, no Rio de Janeiro, guarda numerosos livros de um autor português que tem despertado interesse de estudiosos das letras ibéricas. Trata-se de Francisco Leitão Ferreira, um acadêmico que viveu entre os anos de 1667 e 1735, nascido em Lisboa. Uma pesquisa às cotas bibliotecárias, contudo, pode levar ao termo Floriano Freyre Cita-Cesar, pseudônimo por vezes utilizado pelo acadêmico. Em que pese o mau efeito elocutivo, trata-se de um anagrama rematado de seu nome próprio. Na Academia da Arcadia Romana, da Itália, grêmio do qual também fez parte, Ferreira assumiu o pseudônimo mais poético de Tagideo, epíteto que faz referência ao rio Tejo, ou Tagos, como é chamado na Espanha, composto com a agudeza da tópica cosmográfica, de simbologia pastoril, sobre a qual costumam incidir os epítetos acadêmicos árcades.

Francisco Ferreira é um autor seiscentista que viveu o alvorecer das Luzes na sociedade letrada portuguesa do século XVIII. Vinculado desde jovem à prática das letras cultas, obteve nos estudos e em viagens conhecimentos que beneficiariam sua compreensão do que significava fazer poesia naquele tempo na Europa românica e católica. O enciclopedismo de Diogo Barbosa Machado, conhecidíssimo lexicógrafo setecentista, nos fornece as principais informações sobre a formação e a bibliografia deste "homem de letras" do Antigo Estado português, por meio do longo verbete a ele dedicado na sua Bibliotheca Lusitana (1748) e de um discurso acadêmico denominado Elogio fúnebre do beneficiário Francisco Leitão Ferreira (Cf. BORGHI, 2018, p. 22), escrito e proferido pelo próprio Barbosa Machado na Academia Real da História Portuguesa em 1735, para representar manifestamente nesse grêmio o impacto da morte do colega. 
O verbete da Bibliotheca Lusitana afirma que o presbítero Leitão Ferreira tivera como tutores apostólicos dois prelados italianos que o teriam apresentado ao ambiente acadêmico da Arcádia em Roma, com o que ele granjeara fazer parte da célebre Academia da Arcadia Romana. A partir de uma viagem para aprimorar estudos em Itália, cresceu abertamente a fama da erudição do laureado pároco lisboeta. Na história da literatura portuguesa, não é este o primeiro registro sobre a importância de viagens de estudos de seus letrados à países da Europa, nomeadamente à Itália, nação que, antes do afrancesamento oitocentista, constituíra alguns modelos ou códigos sócio-culturais que foram imitados no continente europeu.

Marcantes foram os efeitos resultantes da intensa efusão de ritmos, metros, possibilidades sonoras dos versos, de arte poética, enfim, que Francisco Sá de Miranda (1495-1558) vivenciara na Itália quando de

Francisco

Leitão

Ferreira, poeta e acadêmico sua estadia entre os anos de 1521 a 1527, intervalo no qual entrara em contato com a poesia de nomes como Garcilaso de la Vega, J. Sannazzaro, Pietro Bembo, Vittoria Colonna, a marquesa de Pescara, poetas que estavam no núcleo duro do aperfeiçoamento dos versos longos, mormente o endecassílabo, que viria, daí a pouco tempo, a ser incorporado ao patrimônio do sistema versificatório da língua portuguesa, por ação da germinal síntese poética operada por Luís de Camões. Mais do que um "trazer um verso da Itália", esta contribuição de Sá de Miranda diz respeito ao descortinar de toda uma reapropriação de modelos de imitação poética e retórica vindos das Antiguidades e, pontualmente, diz respeito à incorporação de modelos poéticos que revitalizariam a poesia em língua portuguesa de modo definitivo com a construção da chamada Medida nova.

Logo na segunda metade do mesmo século XVI, outro Francisco vai pesquisar em Roma, desta feita dedicando-se a estudar a pintura: Francisco de Holanda (1517-1584). Viajando na condição de pesquisador bolseiro fomentado pela Coroa que, preocupada com a crescente ingerência da ação de burgueses no seio da sociedade portuguesa, investia na formação de sua fidalguia, Holanda igualmente faria parte do erudito ciclo de poetas e pensadores em Roma, nomeadamente a mesma Vittoria Colonna, Miguel Ângelo, Lattanzio Tolomei e Diogo Zapata, entre outros, posteriormente ficcionalizados como personagens nos aplaudidos Diálogos publicados pelo Francisco pintor após seu retorno a Portugal, circa 1541. Paralelamente ao fato histórico anteriormente referido quanto a Sá de Miranda, os textos de Holanda inseriram a corte lisboeta no debate europeu sobre o estatuto de nobreza das, por nós chamadas artes plásticas, 
Maria do

Socorro

Fernandes de

Carvalho

defendendo sua liberalidade e a elevação da pintura. Esse debate nada tem de anódino como o lugar sem realce que Holanda costuma ocupar no geral da historiografia portuguesa pode deixar transparecer. De fato, tratava-se do mais elevado debate sobre os lugares político-sociais das técnicas e disciplinas, a importância do estudo para a conformidade da nobreza na sociedade de corte que Lisboa queria espelhar, o tabelamento de impostos trabalhistas, o efetivo político do mecenato, de resto, toda a "política cultural", como se diria hoje em dia.

Os três portugueses realizam efetivamente o protocolo constante no modelo civilizatório das cortes absolutistas da Europa do Antigo Estado, segundo o qual ao homem de corte não bastam qualidades que manifestem sua virilidade e poderio, mas igualmente necessário era granjear a aquisição de virtudes morais e políticas por meio do estudo e do saber. Um dos meios para o enriquecimento de virtude, ensina a doutrina desta sociedade de corte, é adquirir saberes ao viajar, conhecendo o mundo. Na repartição XXV - Culta repartición de la vida de um discreto, do livro El Discreto (1646), Baltasar Gracián expõe nestes termos uma expressão dessa doutrina:

Empléo el segundo en peregrinar, que fue gusto peregrino, segunda felicidad para un hombre de curiosidad y buena nota. Buscó y gozó de todo lo bueno y lo mejor del mundo, que quien no ve las cosas, no goza enteramente delas; va mucho de lo visto a lo imaginado. Más gusta de los objectos el que los ve una vez que el que muchas, porque aquélla se gozan y las demás enfadan; consérvase en aquellas primícias el gusto si que las roce la continudad; el primer día es una cosa para el gusto de su dueño, todos los demás para el de los extraños. Adquiérese aquella ciência experimental, tan estimada, de los sabios, especialmente quando el que registra, atende y sabe reparar, examinándolo todo, o con admiración o con desengaño. Trasegó, pues, todo el universo y paseó todas sus políticas provincias: la rica España, la numerosa Francia, la hermosa Inglaterra, la artificiosa Alemania, la valerosa Polonia, la amena Moscovia y todo junto en Italia. Admiró sus más célebres emporios, solicitando en cada ciudad todo lo notable, así antiguo como moderno: lo magnífico de los templos, lo suntuoso de sus edificios, lo acertado de su gobierno, lo entendido de sus ciudadanos, lo lucido de su nobleza, lo docto de sus escuelas y lo culto de su trato. (GRACIÁN, 2001, p.196 [grifos meus]). 
Pelo trecho final da citação, entende-se facilmente com o que Francisco de Holanda se deslumbrara na escolada terra da Vila dos Medicis. Quer dizer, além de "conversar com os mortos", ou seja, ler e refletir sobre a doutrina de autores de tempos passados, antigos ou velhos, ao completo homem de corte não poderia faltar o elemento da experiência do conhecimento de outras terras, sociedades, modos de vida e obras. Este argumento aparece em relevantes livros do Seiscentos, a exemplo das Novelas ejemplares de Miguel de Cervantes, nomeadamente a novela El licenciado Vidriera, cujo protagonista realiza todo esse ciclo de estudos e vivência no exterior previstos para a conclusão de sua formação.

Esse postulado de discrição por meio do granjear virtudes pelo desnudamento "do outro", diríamos hoje em dia, buscando no exterior

Francisco

Leitão

Ferreira, poeta e acadêmico do país de origem a construção de saberes nos domínios da linguagem, da política, das ciências e das artes, que sintetizamos no termo viagem, deixou de ter maior significado para o homem romântico, em cujo ideal de formação aparecia certo "movimento para dentro", se quisermos usar esta expressão. Efetivamente, é o que transparece do sentido da expressão "cor local", pressuposto do programa do Romantismo nas artes, como se sabe, que visava o conhecimento de suas próprias instituições, de seu interior, "de si”. Transparece igualmente de um livro marcante do Romantismo em língua portuguesa, a partir já do título: Viagens na minha terra, (publicada em 1843), escrita por Almeida Garrett, escritor empenhado programaticamente com a representação dos elementos nacionais lusitanos. A narrativa confessional destas Viagens incide na exposição e digressão crítica sobre a paisagem interior, a história autóctone e o devir de Portugal. No Antigo Estado, todavia, aprende-se necessariamente indo para fora de seu lugar, - para a Itália, tão melhor, também Índias, ou Novo Mundo. Contudo, é notório que tal conhecimento devia primeiramente ser conquistado via estudo e dedicação, e sempre a partir da chancela dos saberes autorizados pelas várias instituições: livros, universidades, academias, ciclos letrados, paços etc. O conhecer empírico desprovido do lastro institucional nunca provia virtude ao seu candidato.

É este o significado que encorpa a viagem de estudos feita por Francisco Leitão Ferreira à Espanha e à Itália, pelo estudo das letras nas línguas circulantes na Itália da virada do século XVII ao seguinte. Foi lá que Ferreira entrou em contato com os mais recentes debates 
que envolviam os temas das letras, das artes e das instituições cultas em funcionamento naquele país e granjeou fazer parte da conceituosa Accademia dell'Arcadia romana. Ferreira entabulou o estudo de autores franceses, espanhóis, como Baltasar Gracián, e principalmente italianos, como Emanuele Tesauro, Sforza Palavicino, Matteo Peregrini, entre vários outros.

Esse modelo de cortesania, que pode ser expresso por meio do

Maria do Socorro Fernandes de Carvalho topos das Armas e letras, aparece em muitos gêneros textuais e atesta o sentido de cosmopolitismo alcançado pelos autores referidos. Segundo Luís S. Rebelo, no século XVII, o topos das Armas e letras é vinculado à doutrina do perfeito cortesão, modelo civil pelo qual o homem de corte almejava alcançar fama e destacar-se do vulgo, representando-se como sujeito discreto que sabe preferir honra à riqueza (Cf. REBELO, 1982). A importância da assimilação de conhecimentos e da imitação de modelos retórico-poéticos de outros lugares e línguas surge quando pensamos que, no caso deste prior, não se consolida em armas, expressão pela qual entendemos denotativamente a força do poder estatal pela posse de armas, com certeza, mas por extensão, entendemos também o poder de mando e submissão, o saber mandar politicamente, conforme era demandado ao príncipe e ensinado nos múltiplos espelhos de príncipe aos cortesãos. No caso de Ferreira, o que importou de seu espectro de conhecimento foi a composição de uma síntese especulativa da amplitude das letras seiscentistas, conforme doutrinação importada em Portugal da Itália e da Espanha.

Estamos falando do livro Nova Arte de Conceitos, tratado em dois volumes, impressos em 1715 e 1721, o qual compilou discursos acadêmicos proferidos na Academia dos Anônimos, em Lisboa. Esse livro é muito importante para o estudioso destas letras porque é um epítome da rarefeita "teorização" efetuada em língua portuguesa em torno das questões fundamentais da linguagem, das artes retórica e poética, da gramática, dos gêneros e sub-gêneros textuais praticados pela poesia e prosa daqueles anos seiscentos. Dada a rarefação especulativa em língua nacional, compreende-se factualmente a relevância do sopro vitalizador vindo da península itálica e da hispânia. Com essas lições acadêmicas, Ferreira efetua o epítome das principais tratadísticas circulantes na Europa no decorrer do século XVII acerca da noção de engenho e de conceitos adjacentes à poesia nas artes da linguagem, além de tratar de várias virtudes retóricas do texto bem escrito. A partir da especulação 
acerca do conceito de engenho, Ferreira consolida o perfil do homem de corte setecentista, as virtudes que deve granjear no trato social e o papel que o conhecimento e domínio da linguagem exercem nessa sociedade, destacando o caráter civilizatório da palavra e a própria noção de entendimento pela linguagem. As agudezas da poesia e da prosa são entendidas como entimemas urbanos, para cuja construção concorre o engenho como virtude natural dotado de duas virtudes: perspicácia e destreza. Vê-se que, em toda a Nova arte de conceitos, estão presentes as concepções do que seja poesia, discurso de ficção, retórica e agudeza que preencheram esse debate no decurso do século XVII, nomeadamente as doutrinas de Baltasar Gracián e Emanuele Tesauro.

A propósito da Itália, o paralelo entre Roma e Lisboa é o argumento central dado à amplificação de outro texto de Leitão Ferreira,

Francisco

Leitão

Ferreira, poeta e acadêmico ainda menos conhecido, o livro Idea poetica, publicado em 1709, de que temos dois exemplares na Biblioteca Nacional, no Rio de Janeiro. Trata-se de uma longa ekphrasis em comemoração ao casamento real do príncipe herdeiro português. Vou falar mais detidamente sobre essa Idea.

O livro Idea poetica, epithalamica, panegyrica, que servio no arco triunfal que a nação italiana mandou levantar na occasião em que as Magestades dos... reyes de Portugal, Dom Joam V. e D. Marianna de Austria, foram à cathedral de Lisboa... 22 de dezembro de 1708 (...) consiste numa primorosa descrição em prosa e verso de um arco triunfal construído em comemoração ao casamento real português. Sobre o arco triunfal, suposto referente histórico mandado construir pelo governo romano, a partir do qual a voz autoral faz o epitalâmio, não fica comprovado se existiu materialmente, como é comum na convenção de descrição de imagens. o que temos de fato é um discurso com voz enunciativa mista, em verso e prosa, de um copioso elogio das virtudes da monarquia lusitana, composto a partir da analogia entre a grandeza do império de Roma, antiga e gentia, e a sublimidade do império de Portugal moderno e católico.

Desde o início do discurso, a Idea traz à tona a necessidade de incorporação da representação da monarquia:

\footnotetext{
Entre os relevantes benefícios com que os Príncipes conquistão os affectos de seus vassalos, dous são os que mais illustram a real beneficência, ser visto o Príncipe publicamente de seus povos com decoro, \& magestade, porque assim anda sempre nos
} 
olhos de grande, \& pequenos (...) o outro benefício é deixar de si gloriosa posteridade, porque nesta não somente se estabelece a razão de estado das allianças, \& se assegura a paz da Monarquia na Coroa, mas também multiplica o Príncipe numerosas ideas de si mesmo, sendo a regia índole de cada filho, um sucessivo retrato, em que os povos admirem copiadas ao vivo as paternaes virtudes, como os Penos contemplavão as de Amilcar defundo

Maria do no valeroso Annibal. (FERREIRA, 1709, p. 5 [grifo meu]).

Socorro

Fernandes de

Carvalho
Dadas as razões, com efeito a mais incisiva de todas, a razão de estado, ou seja, a concepção de que pode ser imperativo o uso dos meios para a manutenção do poder se em benefício do bem comum, ainda que seja a força física estatal, por vezes, a Idea segue mostrando como os portugueses costumam aplaudir com solenidade seus monarcas, demonstrando nisso a gratidão pelos benefícios recebidos e para testemunharem publicamente fidelidade e obediência aos mesmos. Portanto, as representações artísticas são entendidas, por esse viés, como um meio de promoção de benefícios ao bem comum. A construção de arcos triunfais, sejam no domínio material dos edifícios monumentais, seja no domínio simbólico dos discursos, é um meio político eficaz, pois tem caráter efetivo no âmbito da ostentação do poder de mando das monarquias do Antigo Estado. Do ponto de vista da doutrina, arcos nada têm de inúteis ou extravagantes.

O discurso segue a disposição recomendada pela retórica de apresentar a matéria atestando sua elevação por referência aos modelos antigos: a nobre nação italiana é versada nestes aparatos magnificentes, serviu de exemplar histórico porque foi a primeira que construiu um arco triunfal para ingresso na cidade de Roma dos augustos governantes, conforme aprendido na Academia romana. Antes de descrever a ordem arquitetônica e a idea poética do arco lusitano, o autor assegura achar proporcionado constatar a antiguidade das máquinas triunfais, ou seja, desses edifícios monumentais, como também da significação a que aludiam por ocasião das pompas dos antigos Estados. Segue no texto dando notícia sobre os primeiros arcos, suas origens e formas primeiras em Roma e passa rapidamente à apresentação do lugar e a fazer a descrição arquitetônica do arco de Lisboa "no largo da Tanoaria, que olha para o Arco do Ouro, porta antiga, \& pública da Cidade" (Idem, p. 8): dois corpos ou volumes de área construída com 80 palmos de altura 
e 70 palmos de largura, sendo o primeiro corpo "constituído pela ordem coríntia" e o segundo por "ordem compósita", rematados ambos por um zimbório oitavado. $\mathrm{O}$ arco contém cinco estátuas, alguns "emblemas, \& tenções simbólicas, \& geroglyficos" que constituem seu "poético adorno", de tudo "proporcionado à majestade do argumento". o papel do poeta Francisco Leitão Ferreira é fazer a ekphrasis dos componentes visuais e textuais presentes no arco. As paráfrases dos emblemas latinos são em verso. As descrições são em prosa.

A estátua cimeira reproduz o deus Jano, signo do sol, aquele que vê o Oriente e o Ocidente. $O$ análogo do astro-rei é notadamente Dom João V, cabeça do Império português, condição pela qual ele é igualmente capaz de vê uma e outra faces do mundo. Ao pé dessa estátua está uma estrofe de versos em latim, de que o poeta oferece a tradução

Francisco

Leitão

Ferreira, poeta e acadêmico a modo de um soneto em língua portuguesa, em cujo argumento o rei romano oferece ao homólogo lusitano as chaves da cidade de Lisboa. Somente o possuidor dessas chaves pode operar a passagem dos tempos passados aos futuros, razão pela qual Jano costuma ser representado numa figura humana com duas faces.

Segue-se um epigrama em latim vertido num segundo soneto, que destaca a ascendência gloriosa do monarca, conforme orientação da retórica de Quintiliano, por exemplo, que ensina que, nas imitações elogiosas (ou vituperantes), o objeto do elogio deve ser caracterizado a partir de lugares-comuns pessoais, que comprovem a justeza do elogio. Daí que Francisco Leitão Ferreira incida sobre os lugares que tipificam o príncipe: origem (genus), nação (natio), pátria (patria), condição (conditio) e "o que aparenta ser" (quid affectat).

Depois vem a descrição da fachada do arco das estátuas imperiais: Roma, figurada como uma matrona de aspecto varonil e a escultura da cidade de Lisboa, personificada noutra matrona varonil, conquanto vestida com a veste real, recostada ao rio Tejo. Análoga de Roma, Lisboa é melhor urbe porque "batizada e católica". o poeta faz a tradução dos dísticos latinos em breves estrofes vernáculas e efetua o elogio da cidade portuguesa que, num curioso quiasmo em prosa, é tomada como "original" de que ser cópia Roma apenas desconfiava. A segunda fachada do arco triunfal é descrita a partir da ekphrasis da estátua de Mercúrio, que aqui significa a corrida triunfal de Portugal à felicidade. Outra estátua é descrita: a de Hércules, herói antigo análogo do rei católico na prudência e no triunfo da conquista. 
Após as estátuas, o poeta imita os quadros e escudos reais de Portugal pois, conclui: “Não podião as façanhas Portuguesas ter mayor panegyrico do que o Escudo heroico das Reaes Armas; nem mais authorizado Historiador, que a mesma verdade divina" (Idem, p. 31). Para rematar essa fachada, o poeta traz um soneto que é excelente na síntese dos primordiais signos da realeza lusitana, complemento do anterior trecho em prosa descritiva. Segue-se o elogio dos "Escudos das armas Maria do pontifícias", emblemas e "geroglyficos" e símbolos reais, sempre mesSocorro Fernandes de Carvalho clando-se prosa com arremate das partes em verso.

O texto Idea poetica por inteiro compõe uma ekphrasis do arco triunfal que, sendo um discurso da ordem da imitação, cuja elaboração é instruída na arte poética, realiza com perfeição a composição do topos das Armas e letras, da ordem da arte retórica. Esee gênero discursivo vincula fortemente a palavra poética à visualidade tanto das imagens criadas por meio das figuras de linguagem, portanto no domínio da poesia, quanto às imagens pictóricas criadas pelas cores e linhas da pintura e volume das artes plásticas da escultura e arquitetura. $\mathrm{O}$ conjunto dos signos palavra, volume e cor é aproveitado nos monumentos públicos, máquinas de representação das virtudes políticas do Estado. O que temos na Idea poetica de Ferreira é já um segundo discurso, em que o acadêmico transpõe para a descrição em prosa e verso, esse conjunto de signos já engrenados na máquina do arco triunfal, ainda que este não exista na concretude do monumento físico. "A pintura imitando com as tintas aos jaspes", o poeta imitando com palavras às tintas do pintor que imitou a natureza. O professor João Adolfo Hansen historia o gênero das ekphrasis em algumas retóricas antigas:

Nos progymnasmata, exercícios preparatórios de oratória escritos por retores gregos entre os séculos I e IV d.C., ekphrasis (de phrazô, "fazer entender", e ek, “até o fim") significa "exposição ou descrição", associando-se às técnicas de amplificação de tópicas narrativas, composição de etopéias e exercícios de qualificação de causas deliberativas, judiciais e epidíticas. Aélio Theon diz que ekphrasis é discurso periegético - que narra em torno - pondo sob os olhos com enargeia, "vividez". Nos seus progymnasmata, Hermógenes a define de maneira semelhante: técnica de produzir enunciados que têm enargeia, presentando a coisa quase como se o ouvido a visse em detalhe. 
O termo também nomeia um gênero do discurso epidítico feito como descrição de caracteres, paixões e obras de arte, esculturas e pinturas, praticado como exercício de eloquência ou declamação (meletê) por filósofos e oradores da "segunda sofística" do século II d.C., como Calístrato, Filóstrato de Lemnos, Luciano de Samósata (...) No caso, a ekphrasis é definida como antighaphai ten graphein, contrafazer do pintado ou emulação verbal que compete com a pintura, descrevendo quadros inexistentes como enargeia. A ekphrasis relaciona-se diretamente com passagens dos “Tópicos I", da Retórica e da Poética, onde Aristóteles escreve sobre a atividade do historiador e do poeta, prescrevendo que devem compor imitando as opiniões tidas por verdadeiras pelos sábios ou pela maioria deles. As opiniões tidas por verdadeiras fornecem causas

Francisco

Leitão Ferreira, poeta e acadêmico

A citação diz tudo de que precisamos para entender o funcionamento desta descrição a partir mesmo de seu título, Idea poetica, pois fica claro que é o conceito da virtude do casal real a Idea que o texto quer fazer saltar à vista do leitor ou ouvinte. A concretude do mármore transmite a ideia de superação da passagem do tempo num aproveitamento do topos sintetizado por Horácio na fórmula exegi monumentum.

A descrição deste arco triunfal elaborada por Ferreira confere ao conjunto da Idea um completo elogio das virtudes do reino de Portugal, como se disse. A evidentia descritiva dos conceitos aparece todavia em situações várias de enunciação, no todo e nas partes do discurso, como por exemplo no aparato genial sobre a incompletude física de alguns monumentos públicos, que nisso fingem certa falta de acabamento em sua construção, conforme o trecho intitulado Sitio, \& descrição architectonica do Arco:

Se bem que este accidental defeito the adquirio mayor realce; porque nas obras magnificas he gênero de grandeza o nam ficarem rematadas, para que da expectação do que serião, se argua que o artífice nam deu por acabada a empresa, grangeando na estimação do mundo duas admirações, uma da excellencia do designio, \& outra do árduo da execução: assim sucedeo na estrutura dessa máquina (FERREIRA, 1709, p. 8-9). 
Mayor realce é precisamente o efeito almejado pelo artifício da evidentia ou enargeia na descrição. Essa ekphrasis o tempo todo refere a instrução retórico-poética de sua própria construção, lembrando ao leitor ou ouvinte a adequação textual, a magnificência da matéria, a elevação do estilo e a homologia dos discursos verbal e visual. A condição retórica aparece mesmo na crítica, bem ao gosto do nascente século XVIII, ao que viria ser considerado excesso das agudezas pelo acúmulo Maria do de ornatos da linguagem: "usando um estilo singelo, sem o recôndito Socorro das metáfora, como deixando lugar a outros, para que vestissem de troFernandes de pos inchados; palavras crespas, \& reboantes" ao julgar os Commentarios Carvalho atribuídos ao rei D. Afonso Henriques no relato do Milagre de Ouriques, escritos, segundo o juízo do acadêmico setecentista, tendo usado o real comentarista da "Rhetorica celeste, sem inchação vangloriosa, compoz uma só metáfora clara, \& perceptível..." (Idem, p. 31-32).

Muitos são os poemas elogiosos, encomiásticos, panegíricos às monarquias europeias. Na Biblioteca Nacional, no Rio de Janeiro, é possível consultar um leque amplo de genetlíacos, epitalâmios, nênias, triunfos, epicédios, elegias, e mais variados sub-gêneros da poesia encomiástica praticada pelos homens de letras luso-brasileiros; em parte deles, o artifício central do poema é a ekphrasis. Os panegíricos fazem o elogio dos feitos vitoriosos de um governante traçando toda a crônica de sua vida, desde alguns remotos ascendentes até o legado político deixado. A título de comparação, destaca-se o longo idílio Lampadário de Cristal, escrito pelo poeta Jerônimo Bahia, mas foge da lembrança um número bastante maior de textos de autores menos conhecidos, acadêmicos como Leitão Ferreira, que praticaram copiosamente o encômio, especialmente entre os séculos XVII e XVIII.

Do nosso autor, menos conhecido como versejador do que orador e historiador, identifiquei entretanto em nossa BN uma série prodigiosa de versos. Vários desses títulos são editados em coletâneas de múltiplos autores, devido a dificuldade em publicar livros individuais. Assim, há títulos que, embora sejam atribuídos na base de dados a Leitão Ferreira, contêm livros inteiros ou textos avulsos de outras pessoas; do mesmo modo há textos seus imersos em antologias preparadas por outrem.

Há duas imitações de sonetos de Luís de Camões, exercício o mais comum no século XVII, todo devedor da mímesis de Os Lusíadas, intitulado Affectos lusitanos, que na intempestiva morte da serenissima senhora $D$. Isabel Luisa Iosefa, infanta de Portugal, o mesmo reyno offerece a immortal fama, 
perenne duraçaõ, \& perpetua memoria de seu soberano, real, \& augusto nome; glosa ao decimonono soneto das rimas do grande Luis de Camoens, do ano de 1691, uma glosa ao soneto Alma minha gentil que te partiste, seguido de um elogium sepulcrale. Também como imitação de Camões temos a Memoria sepulchral epitaphio saudoso esculpido pello sentimento sobre a sepultura da sempre augusta e serenissima senhora D. Maria Isabel de Neuburg, rainha de Portugal; glosa ao octagésimo sexto soneto do grande Luis de Camões que anda na segunda centuria das suas rimas comentadas por seu illustrador Manoel de Faria \& Souza... Sem que tenha sido possível fixar a data de publicação dessa imitação, a glosa ao soneto Os olhos, onde o casto amor vivia, editada com tipografia já bastante modernizada, certamente é do século XVIII.

Diogo Barbosa Machado, no citado Elogio fúnebre do beneficiado, afirma que Ferreira elaborou o texto a seguir por ocasião da consagração

Francisco Leitão Ferreira, poeta e acadêmico pontifícia em Roma, apenas posteriormente publicados: Auspicios encomiasticos, em a felicissima promoçam ao cardinalato do eminentissimo senhor George Cornaro ... emanada em 22 de julho de 1697, pelo Oraculo Santissimo de Innocencio XII ... Trata-se de poemas anagramáticos, que trazem cifras numéricas como chave de leitura, de diversas autoridades poéticas. ${ }^{2}$ Neste caso do item Ao Eminentissimo, \& Reverendissimo Senhor dom Nuno da Cunha, Presbytero Cardeal... Auspicio encomiastico que tem por assumpto a prediçam que o Bemaventurado Sam Felix de Cantalicio fez ao... Cardeal Felix de Montealto, que no Summo Pontificado se chamou Xisto $V$, temos um soneto encomiástico.

O texto Ao... senhor D. Manoel infante de Portugal, protector, \& juiz da festa com que os padres capuchinhos italianos celebram no seu hospicio desta cidade a canonizaçam de Sam Felix de Cantalicio...traz um soneto em folha volante com o curioso incipit: Poem-se Deus em figura de Menino.

Maior destaque merece o título Berço natalício dedicado ao felice nascimento do Augusto primogenito das magestades lusitanas D. Pedro II \& D. Maria Sofia Isabel de Neuburg Reys, \& Senhores nossos, screvia-o... pois nele temos uma longa silva encomiástica assinada pelo pseudônimo de Floriano Freyre Cita-Cesar. Na verdade, este livro de 1688, que tem início com uma Prosopopeia prologetica em que fallão estas obras com o Leitor, traz vários títulos de nosso e de outros autores dos séculos XVII e XVIII como Manoel Borralho e João Batista da Ponte, este último com um soneto dedicado ao nosso poeta em 1704, segundo Barbosa Machado.

2 Neste mesmo livro, temos a curiosidade de dois poemas laudatórios atribuídos ao conhecido músico e poeta luso-brasileiro Domingos Caldas Barbosa. 
A Idea emblematica é um soneto trazido a público como poema único em folha avulsa com moldura gráfica à mesma persona da descrição Idea poetica. Seu título completo é: Convida-se a magestade...rainha d. Marianna de Austria nossa senhora a applicar os olhos da sua...real devoção ás virtudes com que o Bem-aventurado Sam Felix de Cantalicio floreceo no mundo, \& aos gloriosos dotes com que resplandeceo no Ceo. Idea emblematica. em que se pinta huma aguia imperial fitando os olhos nos rayos do sol, com esta epigrafe: In Splendoribus Sanctorum.

Maria do $\quad$ p primeiro verso sintetiza o lugar de nascimento da ascendência da então Socorro rainha de Portugal, conforme instruíra Quintiliano quanto aos referidos Fernandes de Carvalho lugares-comuns a persona: Ave real, que tendo em Austria o ninho.

Datado de 1707, temos um soneto e glosa cuja cota bibliotecária afirma como título: Musa typographica, seu argumento, qve sendo servido el-rey... d. João $V$ de ver o veo de hvma imprensa se lhe estampou este soneto extemporaneo: do qual offerece agora a glosa o beneficiado Francisco Leytam Ferreyra. E um epigrama em latim, publicado em folha avulsa com moldura gráfica, noutra cota, intitulado Serenissimae dominae d. Franciscae Theresiae... Portugalliaes infanti... celebritatem canonizationis S. Felicis de Cantalice... inverventu benigno decoranti.

Como disse acima, e é praxe neste período em estudo, há textos de vários autores espalhados pelas numerosas antologias coletivas. É o caso de certo Soneto jocoso de Leitão Ferreira, desse modo denominado, cuja didascália registra a diatribe da fuga de certo jurisconsulto ridicularizado no poema: À fugida de um Dom Francisco Ronquilho, Jurisconsulto e Governador das Armas de Cidade Rodrigo. No soneto, há o trocadilho entre certo Bartolo bobo, parvo e o nome do jurisconsulto medieval Bártolo, sabendo o leitor que o increpado é um jurisconsulto. Aparentemente essa persona ridicularizada nada entende de armas, apesar da pompa bélica do título. O poema traz toda uma conotação ridicularizante dos termos militares. Mais conhecido é o Romance de Fernaõ Freire Cita-Cesar em occasião de boas festas a hum compadre Mercador de livros, $e$ Thesoreiro da Bulla, uma peça de poesia jocosa que interessaria à história do livro e da leitura, pois sua matéria trata de um pedido de entrega de livros a um livreiro. Como romance, é muito adequado pelo prosaísmo da circunstância: nas vésperas de Natal, uma persona pede que o compadre livreiro lhe entregue um livro demandado, sugere pagar a dívida com um "leitão" e reclama a respeito de vendas anteriores. O poema agrada pela linguagem simples do estilo pedestre e pelo divertido de uma arguição descomprometida no afeto da amizade. 
É como prosador, contudo, que Leitão Ferreira é mais conhecido: historiador, missivista, catalogador, além de pároco. Escrito em prosa encomiástica, temos na BN o Elogio funebre do...padre Fr. Miguel de S. Maria...Disse-o o beneficiado Francisco Leitão Ferreira, em 13 de mayo de 1728. Embora na tratadística seu livro mais prestigiado seja a Nova arte de Conceitos, registre-se ainda que nosso acadêmico elaborou o Cathalogo Chronologico-Critico dos Bispos de Coimbra, pronto em 1724 e foi historiador da universidade portuguesa, tendo publicado as Notícias Cronológicas da Universidade de Coimbra, de 1729. Foi acadêmico em vários grêmios: dentre as já referidas, também a Academia Real da História Portuguesa.

\section{REFERÊNCIAS}

BORGHI, Gustavo L. N. Uma introdução ao estudo da noção de engenho: notas para uma leitura da Nova Arte de Conceitos (17181721), de Francisco Leitão Ferreira. Dissertação (Mestrado em Literatura Portuguesa), FFLCH, Universidade de São Paulo, 2018.

CERVANTES, Miguel. El licenciado Vidriera. In: . Novelas ejemplares (II). Org. J. B. Avalle-Race. Madrid: Editorial Castalia, 1982.

FERREIRA, Francisco Leitão. [Floriano Freyre Cita-Cesar]: Idea poética, epithalamica, panegyrica, que servio no arco triunfal que a nação italiana mandou levantar na occasião em que as Magestades dos... reyes de Portugal, Dom Joam V. e D. Marianna de Austria, foram à cathedral de Lisboa... 22 de dezembro de 1708. Lisboa [Portugal]: Na Officina de Valentim da Costa Deslandes, 1709.

Nova arte de Conceitos que com o titulo de Licções Academicas na publica Academia dos Anonymos de Lisboa, dictava, e explicava o beneficiado Francisco Leytam Ferreira, academico anonymo. Lisboa Occidental: Na officina de Antonio Pedrozo Galram, 1718-1721. 2 v.

Affectos lusitanos, que na intempestiva morte da serenissima senhora D. Isabel Luisa Iosefa, infanta de Portugal, o mesmo reyno offerece a immortal fama, perenne duraçaõ, \& perpetua memoria de seu soberano, real, \& augusto nome; glosa ao decimonono soneto das rimas do grande Luis de Camoens. Lisboa : Na Officina de Domingos Carneyro, 1691. 
Ao Eminentissimo, \& Reverendissimo Senhor dom Nuno da Cunha, Presbytero Cardeal... Auspicio encomiastico que tem por assumpto a prediçam que o Bemaventurado Sam Felix de Cantalicio fez ao... Cardeal Felix de Montealto, que no Summo Pontificado se chamou Xisto V. Soneto. - [S.n.t.]. : [s.n.].

Ao... senhor D. Manoel infante de Portugal, protector, \&

Maria do

Socorro

Fernandes de

Carvalho

juiz da festa com que os padres capuchinhos italianos celebram no seu hospicio desta cidade a canonizaçam de Sam Felix de Cantalicio... Soneto. - [S.n.t.]. : [s.n.].

Auspicios encomiasticos, em a felicissima promoçam ao cardinalato do eminentissimo senhor George Cornaro ... emanada em 22 de julho de 1697, pelo Oraculo Santissimo de Innocencio XII ...Lisboa: Na Officina de Manoel Lopes Ferreyra, 1697.

Berço natalício dedicado ao felice nascimento do Augusto primogenito das magestades lusitanas D. Pedo II \& D. Maria Sofia Isabel de Neuburg Reys, \& Senhores nossos, screvia-o... Lisboa: Na Officina de Domingos Carneyro, 1688.

. Convida-se a magestade...rainha d. Marianna de Austria nossa senhora a applicar os olhos da sua...real devoção ás virtudes com que o Bem-aventurado Sam Felix de Cantalicio floreceo no mundo, \& aos gloriosos dotes com que resplandeceo no Ceo. Idea emblematica. em que se pinta huma aguia imperial fitando os olhos nos rayos do sol, com esta epigrafe: In Splendoribus Sanctorum. Soneto.

Memoria sepulchral epitaphio saudoso esculpido pello sentimento sobre a sepultura da sempre augusta e serenissima senhora D. Maria Isabel de Neuburg, rainha de Portugal; glosa ao octagésimo sexto soneto do grande Luis de Camões que anda na segunda centuria das suas rimas comentadas por seu illustrador Manoel de Faria \& Souza... Lisboa: na Officina dos Herdeiros de Domingos Carneiro, 1699.

Serenissimae dominae d. Franciscae Theresiae... Portugalliaes infanti... celebritatem canonizationis S. Felicis de Cantalice... inverventu benigno decoranti. Epigramma. 
GRACIÁN, Baltasar. El Discreto. In: Obras Completas. Intr. Aurora Egido, ed. de Luis Sánchez Laílla. Madrid: Espasa Calpe, 2001.

HANSEN, J. A. Categorias epidíticas da ekphrasis. Revista USP, n.71, set/out/nov, ano 2006, p.85-105.

HOLANDA, Francisco de. Da Pintura Antiga. Lisboa: Imprensa Nacional - Casa da Moeda, 1983.

Francisco

Leitão

REBELO, Luís de Sousa. A tradição clássica na literatura portuFerreira, poeta guesa. Lisboa: Livros Horizonte, 1982. e acadêmico 
